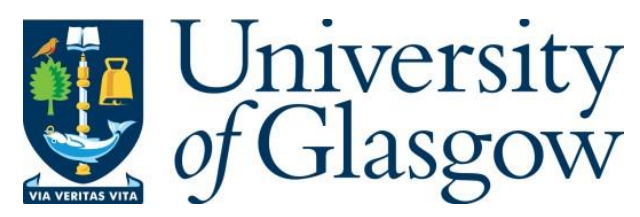

Craig, K. et al. (2019) A mirror coating solution for the cryogenic Einstein telescope. Physical Review Letters, 122(23), 231102.

There may be differences between this version and the published version. You are advised to consult the publisher's version if you wish to cite from it.

http://eprints.gla.ac.uk/186572/

Deposited on: 14 May 2019

Enlighten - Research publications by members of the University of Glasgow

http://eprints.gla.ac.uk 


\title{
A Mirror Coating Solution for the Cryogenic Einstein Telescope
}

\author{
Kieran Craig, ${ }^{1}$ Jessica Steinlechner, ${ }^{1,2}$ Peter G. Murray, ${ }^{1}$ Angus S. Bell,,${ }^{1}$ Ross Birney, ${ }^{3}$ Karen Haughian, ${ }^{1}$ Jim \\ Hough, ${ }^{1}$ Ian MacLaren, ${ }^{1}$ Steve Penn, ${ }^{4}$ Stuart Reid,${ }^{3}$ Raymond Robie, ${ }^{1}$ Sheila Rowan, ${ }^{1}$ and Iain W. Martin ${ }^{1, *}$ \\ ${ }^{1}$ SUPA, School of Physics and Astronomy, University of Glasgow, Glasgow, G12 8QQ, Scotland \\ ${ }^{2}$ Institut für Laserphysik und Zentrum für Optische Quantentechnologien, \\ Universität Hamburg, Luruper Chaussee 149, 22761 Hamburg, Germany \\ ${ }^{3}$ SUPA, Department of Biomedical Engineering, University of Strathclyde, Glasgow, G1 1QE, Scotland \\ ${ }^{4}$ Department of Physics, Hobart and William Smith Colleges, Geneva, NY 14456, USA
}

(Dated: May 7, 2019)

\begin{abstract}
Planned, cryogenic gravitational-wave detectors will require improved coatings with a strain thermal noise reduced by a factor of 25 compared to Advanced LIGO. In this article, we present investigations of $\mathrm{HfO}_{2}$ doped with $\mathrm{SiO}_{2}$ as a new coating material for future detectors. Our measurements show an extinction coefficient of $k=6 \times 10^{-6}$ and a mechanical loss of $\phi=3.8 \times 10^{-4}$ at $10 \mathrm{~K}$, which is a factor of 2 below that of $\mathrm{SiO}_{2}$, the currently used low refractive-index coating material. These properties make $\mathrm{HfO}_{2}$ doped with $\mathrm{SiO}_{2}$ ideally suited as a low-index partner material for use with $\mathrm{a}-\mathrm{Si}$ in the lower part of a multimaterial coating. Based on these results we present a multimaterial coating design which, for the first time, can simultaneously meet the strict requirements on optical absorption and thermal noise of the cryogenic Einstein Telescope.

PACS numbers: 42.79.Wc, 77.84.Bw, 81.15.Cd, 81.40.Gh
\end{abstract}

Introduction - During the first two observing peri- ${ }^{54}$ ods of advanced interferometric gravitational-wave de- 55 tectors, 10 gravitational-wave signals from binary black 50 hole mergers and one from a binary neutron star inspiral ${ }_{57}$ have been measured [1 6]. To improve upon the sensi- 58 tivity of the current generation of detectors, Advanced 59 LIGO [7, 8] and Advanced Virgo [9], it is essential to re- 60 duce coating thermal noise (CTN). The CTN amplitude 61 spectral density is proportional to the square root of the 62 mirror temperature [10]. Therefore, gravitational-wave 63 detectors such as KAGRA [11, 12] and the low frequency detector of the planned Einstein Telescope (ET-LF) $\left[13{ }_{65}^{64}\right.$ will operate at low temperatures. At frequencies around ${ }_{60}$ $10 \mathrm{~Hz}$, ET-LF will be 100 times more sensitive than $A d-{ }^{67}$ vanced LIGO and Virgo at the same frequency. This ${ }_{68}$ improved sensitivity will increase the observable volume ${ }_{69}^{68}$ of space by a factor of $100^{3}$ and open up the $1-10 \mathrm{~Hz}_{70}{ }^{69}$ frequency band. This may allow multiple detections of known young pulsars [14, first detections of a Galactic ${ }_{72}$ Type Ia supernova [15], and many distant - and possibly new types of - sources. The expansion of the frequency range will also allow inspirals to be observed for a longer ${ }^{74}$ time before the final merger events.

The interferometer mirror coatings are made of alter- ${ }_{77}$ nating layers of materials with low and high refractive ${ }_{78}$ index $n$. In the simplest case, the layers are a quarter of 79 a wavelength (QWL) in optical thickness $\left(n\right.$ multiplied $_{80}$ with the geometric thickness $t$ ). To avoid thermal defor- ${ }_{81}$ mation of the mirrors, and to maintain the desired cryo- ${ }_{82}$ genic temperature, heating must be minimised. There- ${ }_{8}$ fore in addition to low CTN, low optical absorption at ${ }_{84}$ the ppm $\left(10^{-6}\right)$ level is required.

$\mathrm{SiO}_{2}$ and $\mathrm{Ta}_{2} \mathrm{O}_{5}$ (or $\mathrm{Ta}_{2} \mathrm{O}_{5}$ doped with $\mathrm{TiO}_{2}$ [16]), de- 86 posited using ion-beam sputtering (IBS), are widely used ${ }_{87}$ coating materials with very low absorption and scattering [17. A complication of cooling is that CTN is proportional to the square root of the mechanical loss, which is temperature dependent. Both $\mathrm{SiO}_{2}$ and $\mathrm{Ta}_{2} \mathrm{O}_{5}$ (doped or un-doped) show mechanical loss peaks at low temperatures [18 20]. There is some uncertainty if these peaks are present in multilayer coatings formed from these materials 21, 22. However, it is clear that the mechanical loss is too high to meet the sensitivity requirements of ET-LF.

Another complication is that fused silica, the currently-used mirror substrate material, is not suitable for low temperature operation due to a large peak in mechanical loss at around $40 \mathrm{~K} 23-25]$. For ET-LF, the use of crystalline silicon (c-Si) is planned 13 - the material is also used for the mechanical spacer (at $124 \mathrm{~K}$ ) in stable reference cavities for optical frequency standards [26]. c$\mathrm{Si}$ is not transparent at $1064 \mathrm{~nm}$. Therefore a change to a longer laser wavelength is required [27, with $1550 \mathrm{~nm}$ planned for ET-LF.

Amorphous silicon (a-Si) is a very interesting coating material, due to low mechanical loss at low temperatures [28, 29. Currently, the best estimated absorption for a highly-reflective multilayer a-Si $/ \mathrm{SiO}_{2}$ coating is $7.6 \mathrm{ppm}$ at $1550 \mathrm{~nm}$ and room temperature $\left(k_{\mathrm{aSi}}=\right.$ $1.22 \times 10^{-5}$ ) 30]. There is also potential for further reduction at a higher wavelength and a lower temperature [31, 32. To obtain the minimum optical absorption in a-Si, heat-treatment at $400^{\circ} \mathrm{C}$ is required. Thus a low-index partner material also must have good optical properties and mechanical loss at this heat-treatment temperature.

Using a-Si (instead of $\mathrm{Ta}_{2} \mathrm{O}_{5}$ ) in a highly-reflective coating with $\mathrm{SiO}_{2}$ would significantly decrease CTN at 


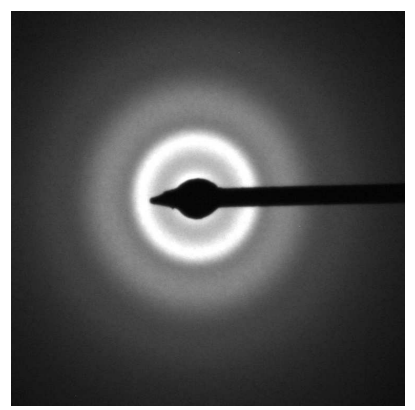

FIG. 1. Electron diffraction pattern of the $600{ }^{\circ} \mathrm{C}$ heat-treated silica doped hafnia coating showing the coating to still be amorphous. This pattern is representative of those measured at lower heat-treatment temperatures.

low temperatures. However, this decrease is limited by the mechanical loss of the $\mathrm{SiO}_{2}$ layers. To meet the ETLF requirements it is therefore essential to find an alternative low-index material for combination with a-Si.

This letter presents IBS $\mathrm{HfO}_{2}$ doped with $\mathrm{SiO}_{2}$ $\left(\mathrm{SiO}_{2}: \mathrm{HfO}_{2}\right)$ as a low-index material for ET-LF coat-128 ings. $\mathrm{HfO}_{2}$ films have been observed to be partially129 poly-crystalline, with the degree of crystallinity increas-130 ing upon heat-treatment. This poly-crystalline structure131 causes a problematically high level of optical scatter-132 ing 33. However, $\mathrm{HfO}_{2}$ shows lower mechanical loss 33$]^{133}$ than $\mathrm{SiO}_{2}$. Doping $\mathrm{HfO}_{2}$ with $\mathrm{SiO}_{2}$ has been shown'134 to stabilise the coating against crystallization following ${ }^{135}$ heat-treatment at temperatures up to $550^{\circ} \mathrm{C}$ [34, 35. 136 We show that $\mathrm{SiO}_{2}: \mathrm{HfO}_{2}$ used with a-Si can meet the137 optical absorption requirements $(<5 \mathrm{ppm})$ and the $\mathrm{CTN}^{138}$ requirements of ET-LF at an operating temperature of 139 $10 \mathrm{~K}\left[13\right.$ when used together with $\mathrm{SiO}_{2}$ and $\mathrm{Ta}_{2} \mathrm{O}_{5}$ in a140 multimaterial design.

Deposition and heat treatment - Coating mechanical 142 loss was measured with a ring-down technique as de-143 scribed in 18 using cantilevers coated with a $\mathrm{HfO}_{2}{ }^{144}$ layer doped with $27 \% \mathrm{SiO}_{2}$ (measured by X-ray pho-145 toelectron spectroscopy). The coatings were deposited ${ }^{146}$ by CSIRO [36 using IBS. Ellipsometry was used to es-147 timate the thickness of the as-deposited coating to be148 $(483 \pm 3) \mathrm{nm}$. The cantilevers were made of $\mathrm{c}-\mathrm{Si}$, which ${ }_{149}$ has low mechanical loss below $150 \mathrm{~K}$ [37, 38, to maxi-150 mize the sensitivity to the coating loss. Prior to coating ${ }_{151}$ deposition an oxide layer $\left(\mathrm{SiO}_{2}\right)$ was grown on the can- ${ }^{-152}$ tilevers by thermal oxidation, to ensure good adhesion of ${ }_{153}$ the coating. The oxide layer was approximately $20 \mathrm{~nm}_{154}$ thick, which was also measured via ellipsometry.

155

Optical coatings are commonly heat-treated to reduce 156 the stress and optical absorption 39. Coating mechan-157 ical loss is also often strongly dependent on heat treat-158 ment [19]. Therefore, the coated cantilevers were heat ${ }_{159}$ treated for 24 hours at temperatures of 150, 300, 400 and $_{160}$ $600^{\circ} \mathrm{C}$ by CSIRO to cover the typical temperature span ${ }_{161}$ used by commercial vendors. There is some evidence $i_{162}$

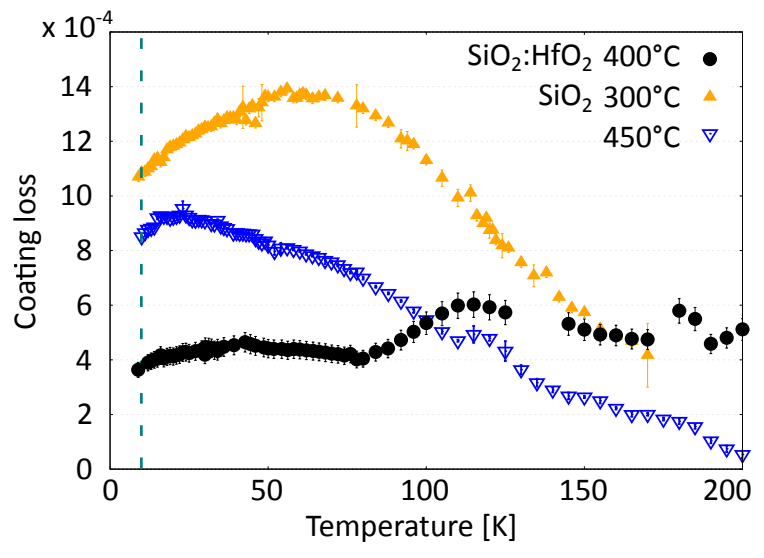

FIG. 2. Temperature dependent coating mechanical loss of $\mathrm{SiO}_{2}: \mathrm{HfO}_{2}$ heat treated at $400{ }^{\circ} \mathrm{C}$ (black circles) measured on a resonant mode at $1.4 \mathrm{kHz}$. Also shown is the mechanical loss of an IBS $\mathrm{SiO}_{2}$ coating at different heat-treatment temperatures 41. The dashed, vertical line marks a temperature of $10 \mathrm{~K}$.

the literature of the growth of a few $\mathrm{nm}$ of oxide due to heat treatment for $\mathrm{HfO}_{2}$ films on c-Si [0]: although it should be noted that this is predicted to occur at higher temperatures than used here. Our ellipsometry measurements showed no significant variation in thickness of the $\mathrm{SiO}_{2}$-doped $\mathrm{HfO}_{2}$ coating due heat treatment. For the oxide layer, there was no evidence of a significant increase in thickness after heat-treatment at $400{ }^{\circ} \mathrm{C}$ - the temperature used for the mechanical-loss results presented here. For heat treatment at $600^{\circ} \mathrm{C}$, a maximum possible increase in oxide thickness of $6 \mathrm{~nm}$ was estimated. It should be noted that variations of up to $3 \mathrm{~nm}$ were observed for samples with identical heat treatment.

Transmission electron microscope measurements of coatings deposited on $\mathrm{SiO}_{2}$ substrates indicated that all of the heat-treated coatings remained amorphous (see Fig. 11. This keeps optical scattering low and makes $\mathrm{SiO}_{2}$ $\left(\mathrm{SiO}_{2}: \mathrm{HfO}_{2}\right)$ potentially useful as a coating material for gravitational wave detectors.

Mechanical loss and Young's Modulus - The Young's modulus, $Y$, of the coating is required for calculation of the coating mechanical loss 49 . For $\mathrm{SiO}_{2}: \mathrm{HfO}_{2}, Y=$ $180 \mathrm{GPa}$ was calculated [50 using the moduli of both $\mathrm{SiO}_{2}$ and $\mathrm{HfO}_{2}$ (see Tab. I).

The mechanical losses of several bending modes in the frequency range $0.5 \mathrm{kHz}$ to $9.5 \mathrm{kHz}$ were measured between $10 \mathrm{~K}$ and $200 \mathrm{~K}$. After a complete measurement cycle, the cantilever was re-clamped and the measurements repeated. This ensures that unintentional variations in the clamping procedure did not affect the results. The mechanical loss of the coatings was calculated by comparing the mechanical loss of the coated c-Si cantilevers with nominally identical oxidized, uncoated samples using [49. Underestimating the oxide thickness of the heattreated, coated samples would result in a small overesti- 
TABLE I. Material properties used for CTN calculations. The ${ }^{180}$ heat treatment temperature for the losses $(\phi)$ was $450{ }^{\circ} \mathrm{C}$ for ${ }^{181}$ $\mathrm{SiO}_{2}$ and $400^{\circ} \mathrm{C}$ for all other materials, with loss values at ${ }^{182}$ $600^{\circ} \mathrm{C}$ in brackets.

\begin{tabular}{|c|c|c|c|c|}
\hline Material & $\begin{array}{c}\phi\left(\times 10^{-4}\right) \\
10 \mathrm{~K} \\
\end{array}$ & $n$ & $k\left(\times 10^{-5}\right)$ & $Y[\mathrm{GPa}]$ \\
\hline $\begin{array}{l}\mathrm{SiO}_{2} \\
\mathrm{HfO}_{2}\end{array}$ & 8.5 (5) 41 & 1.44 42] & $0.008^{*}$ & 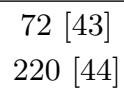 \\
\hline $\mathrm{SiO}_{2}: \mathrm{HfO}_{2}$ & $3.8 \pm 0.3$ & 1.9145 & $0.40 \pm 0.09$ & 180 45 \\
\hline $\mathrm{Ta}_{2} \mathrm{O}_{5}$ & $5(7) 19$ & 2.0546 & $0.008^{*}$ & 14043 \\
\hline $\mathrm{a}-\mathrm{Si}$ & $\leq 0.17 * * 30$ & 3.48 [4] & $1.22 \pm 0.2130$ & 14744 \\
\hline \multicolumn{5}{|c|}{$\begin{array}{l}{ }^{*} \text { Effective } k \text { chosen for } \alpha_{\mathrm{HR}} \leq 0.5 \mathrm{ppm} \text {. This assumes the effecti } \\
k \text { value for the stack at } 1550 \mathrm{~nm} \text { is identical to } 1064 \mathrm{~nm} \text { [4, so } \\
\text { that the absorption just scales with layer thickness. } \\
{ }^{* *} \text { Only measured at room Temperature }\end{array}$} \\
\hline
\end{tabular}

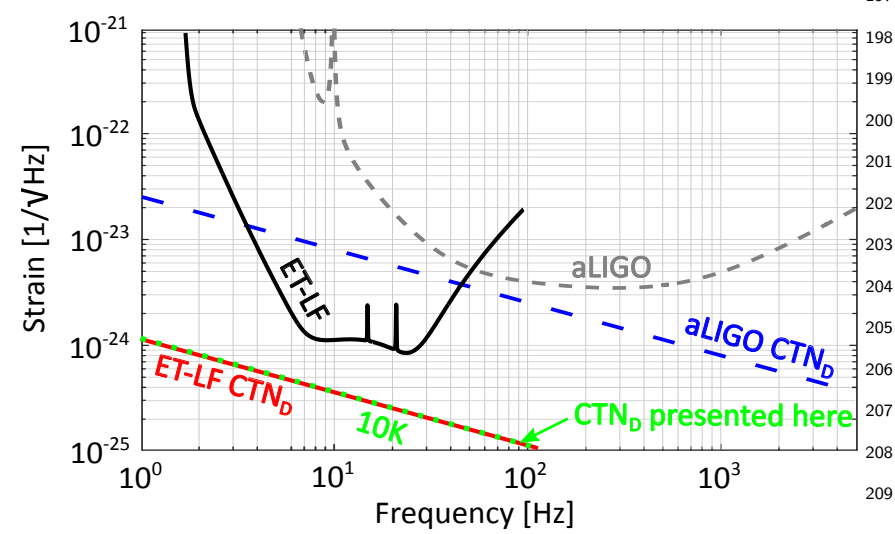

FIG. 3. Design sensitivity (gray, dashed curve) and $\mathrm{CTN}_{\mathrm{D}}$ (blue, dashed line) of Advanced LIGO and design sensitivity210 (black curve) and $\mathrm{CTN}_{\mathrm{D}}$ (red line) of ET-LF. The green, dot-211 ted line shows $\mathrm{CTN}_{\mathrm{D}}$ of our coating (coating (c) in Tab. II ${ }_{212}$ at a mirror temperature of $10 \mathrm{~K}$. mation of the coating loss. For $400^{\circ} \mathrm{C}$ heat treatment, there was no evidence of oxide growth. (For the possi- ${ }_{218}$ ble $6 \mathrm{~nm}$ oxide growth at $600{ }^{\circ} \mathrm{C}$, the coating loss would ${ }_{219}$ change by $\approx 1 \%$.) coating loss for each bending mode. Figure 2 shows $\mathrm{a}_{222}$ representative data series at a mode frequency of $1.4 \mathrm{kHz}_{.223}$ The data shown is for heat-treatment at $400^{\circ} \mathrm{C}$ which is s $_{224}$ the optimum temperature for minimising the absorption 225 in the high-index a-Si layers in a highly-reflective coating 226 stack.

Below $40 \mathrm{~K}$, the loss of the $\mathrm{SiO}_{2}: \mathrm{HfO}_{2}$ heat-treated at 228 $400^{\circ} \mathrm{C}$ is significantly lower than the loss of IBS $\mathrm{SiO}_{2229}$ (heat-treated at $300^{\circ} \mathrm{C}$ and $450^{\circ} \mathrm{C}$ ) as shown in Fig $2{ }_{230}$ $\mathrm{SiO}_{2}: \mathrm{HfO}_{2}$ heat-treated at $400^{\circ} \mathrm{C}$ therefore has great po-231 tential as a low thermal-noise replacement for $\mathrm{SiO}_{2}$ coat-232 ing layers.
Good agreement was obtained between the measured $_{221}$
Optical Absorption - Fused silica discs were coated with $\mathrm{SiO}_{2}: \mathrm{HfO}_{2}$ in the same coating run as the cantilevers used for mechanical loss studies. The absorption of the coatings was measured at $1550 \mathrm{~nm}$ using photothermal common-path interferometry 51 - a technique based on measuring a thermal effect due to optical absorption. The absorption of the as-deposited coating was found to be $(25 \pm 5) \mathrm{ppm}$ for a $500 \mathrm{~nm}$ thick layer. The error originates from variations in absorption across the sample and from reproducibility after realignment. This absorption corresponds to an extinction coefficient of $k=(6.4 \pm 1.3) \times 10^{-6}$. The absorption coefficient of a coating layer, $\alpha$, is related to the extinction coefficient, $k$, by $\alpha=4 \pi k / \lambda$. The total absorption of an HR coating, $\alpha_{\mathrm{HR}}$, also includes the effect of interference in the layers. After heat treatment at $400^{\circ} \mathrm{C}$, which is the optimum temperature for mechanical loss, the absorption reduces to $(16 \pm 3) \mathrm{ppm}\left(k=(4.0 \pm 0.9) \times 10^{-6}\right)$.

Discussion - Figure 3 shows the total strain noise of the Advanced LIGO detectors (gray, dashed curve) at their design sensitivity. The black, solid curve represents the total strain noise of the ET-LF design [13. This strain noise can be converted into displacement noise by multiplying by the detector arm-length ( $4 \mathrm{~km}$ for aLIGO, $10 \mathrm{~km}$ for ET-LF), allowing comparison between detectors to be unbiased by differing arm-lengths. The coating displacement thermal noise of the whole detector, $\mathrm{CTN}_{\mathrm{D}}$, includes contributions from the two input test-masses (ITMs) and the two end test-masses (ETMs) forming the interferometer arm cavities:

$$
\mathrm{CTN}_{\mathrm{D}}=\left(2 \times \mathrm{CTN}_{\mathrm{ETM}}^{2}+2 \times \mathrm{CTN}_{\mathrm{ITM}}^{2}\right)^{\frac{1}{2}} .
$$

The $\mathrm{CTN}_{\mathrm{D}}$ requirement for ET-LF is $\approx 3.6 \times$ $10^{-21} \mathrm{~m} / \sqrt{\mathrm{Hz}}$ at a reference frequency of $10 \mathrm{~Hz}$ (shown in terms of strain noise by the red, solid line) - this is about a factor of 25 below the $\mathrm{CTN}_{\mathrm{D}}$ of Advanced LIGO (blue, dashed line) 52.

The Einstein Telescope design study suggests an operation temperature of $10 \mathrm{~K}$, with the optical absorption of the coating required to be $\leq 5 \mathrm{ppm}[13$. The design transmission of the ETMs is $\mathrm{T} \approx 6 \mathrm{ppm}$ and of the ITMs $\mathrm{T} \approx 7000 \mathrm{ppm}[13$. For the coating materials used in current gravitational-wave detectors, $\mathrm{SiO}_{2}$ and $\mathrm{Ta}_{2} \mathrm{O}_{5}$, $\mathrm{CTN}_{\mathrm{D}}$ would be $\approx 6.45 \times 10^{-21} \mathrm{~m} / \sqrt{\mathrm{Hz}}$ at $10 \mathrm{~Hz}$ and $10 \mathrm{~K}$ (see Tab. III(a)), calculated using [10]. Table II] also shows CTN for the ETMs and ITMs separately. For the ITMs, CTN is lower as fewer layers are required to provide the lower design reflectivity.

Coating (b) in Tab. II demonstrates the potential of using $\mathrm{SiO}_{2}: \mathrm{HfO}_{2}$ as a low-index material alongside a-Si. Based on the results presented here, this combination of materials results in a $\mathrm{CTN}_{\mathrm{D}}=2.4 \times 10^{-21} \mathrm{~m} / \sqrt{\mathrm{Hz}}$ at $10 \mathrm{~K}$. This surpasses the requirement for ET-LF. However, the absorption of this coating, of $\approx(11.9 \pm 2.3) \mathrm{ppm}$ at $1550 \mathrm{~nm}$, exceeds the required value by more than a factor of two. 
TABLE II. CTN of different coatings on cSi substrates at a reference frequency of $10 \mathrm{~Hz}$, a temperature of $10 \mathrm{~K}$ and a beam radius of $9 \mathrm{~cm}$. The material parameters used are shown in Tab. I]

\begin{tabular}{|c|c|c|c|c|c|c|}
\hline Case & $\begin{array}{c}\text { bilayers } \\
\text { ETM (ITM) }\end{array}$ & $\begin{array}{c}\text { Transmission } \\
\text { ETM (ITM) }[\mathrm{ppm}]\end{array}$ & $\begin{array}{l}\text { Heat } \\
\text { treatment }\left[{ }^{\circ} \mathrm{C}\right]\end{array}$ & $\begin{array}{l}\text { CTN ETM (ITM) } \\
\qquad\left[\times 10^{-21} \mathrm{~m} / \sqrt{\mathrm{Hz}}\right.\end{array}$ & $\begin{array}{l}\mathrm{CTN}_{\mathrm{D}} \\
\overline{\mathrm{z}}]\end{array}$ & $\begin{array}{c}\alpha_{\mathrm{HR}} \\
{[\mathrm{ppm}]}\end{array}$ \\
\hline (a) & $18(7) \times \mathrm{SiO}_{2} / \mathrm{Ta}_{2} \mathrm{O}_{5}$ & $4(8500)$ & 600 & $4.0(2.4)$ & 6.6 & 0.6 \\
\hline (b) & $10(4) \times \mathrm{SiO}_{2}: \mathrm{HfO}_{2} / \mathrm{a}-\mathrm{Si}$ & $2(9000)$ & 400 & $1.4(0.9)$ & 2.4 & 11.9 \\
\hline (c) & $2 \times \mathrm{SiO}_{2} / \mathrm{Ta}_{2} \mathrm{O}_{5}+10(4) \times \mathrm{SiO}_{2}: \mathrm{HfO}_{2} / \mathrm{a}-\mathrm{Si}$ & $4.4(6000)$ & 400 & $1.9(1.6)$ & 3.5 & 3.4 \\
\hline \multicolumn{2}{|c|}{ ET-LF requirement 13} & $5(7000)$ & & & $\approx 3.6$ & $\leq 5$ \\
\hline
\end{tabular}
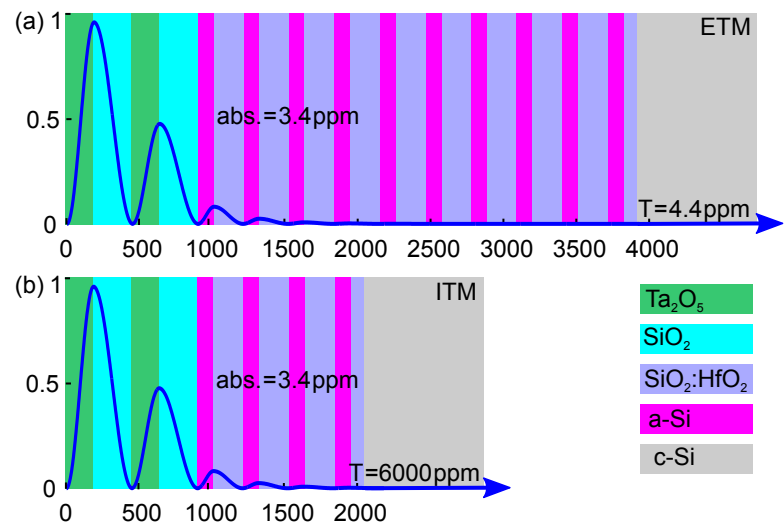

FIG. 4. Design of an ETM and an ITM using a-Si and 270 $\mathrm{SiO}_{2}: \mathrm{HfO}_{2}$ capped with two bilayers of $\mathrm{SiO}_{2} / \mathrm{Ta}_{2} \mathrm{O}_{5}$ to re-271 duce absorption. The layer closest to the substrate is $0.2_{272}$ QWL thick. All other layers are one QWL thick. The blue ${ }_{273}$ line shows the electric field intensity of the laser beam.
A way to further reduce the absorption is the use of $\mathrm{f}^{277}$ a multi-material design [53, 54]. In this design, a few ${ }^{278}$ low-absorbing layers are used on top of the coating to $\mathrm{re}^{-279}$ duce the laser power reaching the lower, higher-absorbing ${ }^{280}$ layers. In our case, two bilayers of $\mathrm{SiO}_{2}$ and $\mathrm{Ta}_{2} \mathrm{O}_{5} \mathrm{re}^{-281}$ duce the light intensity enough for the absorption to be $\mathrm{b}^{282}$ within the ET-LF requirement. This absorption reduction comes at the expense of a slight increase in $\mathrm{CTN}_{\mathrm{D}}{ }^{283}$ which still meets the requirement $\left(3.6 \times 10^{-21} \mathrm{~m} / \sqrt{\mathrm{Hz}} \mathrm{at}_{285}^{284}\right.$ $10 \mathrm{~K}$, see Tab. II( (c)). The exact layer design and the light ${ }^{285}$ intensity inside the coatings is shown in Fig. 4(a) for the ${ }_{287}^{286}$ ETMs and in Fig. 4(b) for the ITMs. The thickness of ${ }_{288}^{287}$ the layer of $\mathrm{SiO}_{2}: \mathrm{HfO}_{2}$ closest to the substrate has been ${ }_{280}^{200}$ adjusted to be 0.2 QWL thick, allowing the transmission ${ }^{209}$ requirement for the ET-LF ITM mirror to be matched ${ }^{209}$ more closely. This coating design therefore meets the ET-LF requirements on thermal noise and optical ab- ${ }^{292}$ sorption. The total $\mathrm{CTN}_{\mathrm{D}}$ strain noise for these coatings ${ }^{293}$ is shown by the green, dotted line in Fig. 3 For this coating heat treatment at $400^{\circ} \mathrm{C}$ was assumed to minimize the optical absorption of the a-Si layers, which increases the mechanical loss of $\mathrm{SiO}_{2}$ and $\mathrm{Ta}_{2} \mathrm{O}_{5}$ compared to coating (a) (see Tab. I).
Note that this coating design is a suggestion for how to use $\mathrm{SiO}_{2}: \mathrm{HfO}_{2}$ calculated based on measurements results of single layers of the different materials. An actual highly-reflective multilayer coating is yet to be produced and verified.

Conclusion - We have shown $30 \% \mathrm{SiO}_{2}: \mathrm{HfO}_{2}$ to be an excellent low-index material for use in highly-reflective mirror coatings together with a-Si. Unlike pure $\mathrm{HfO}_{2}$, $\mathrm{SiO}_{2}: \mathrm{HfO}_{2}$ is stable against crystallization for heat treatment up to $600^{\circ} \mathrm{C}$, which prevents excess scattering - essential for materials to be suitable for gravitational-wave detectors. The mechanical loss of $\mathrm{SiO}_{2}: \mathrm{HfO}_{2}$ at a temperature of $10 \mathrm{~K}$ is significantly lower than observed for pure $\mathrm{SiO}_{2}$. After heat treatment at $400^{\circ} \mathrm{C}$, which is the optimum temperature to minimize the optical absorption of a-Si, the mechanical loss of $\mathrm{SiO}_{2}: \mathrm{HfO}_{2}$ is more than a factor of 2 below that of $\mathrm{SiO}_{2}$.

A multi-material coating made of a-Si and $\mathrm{SiO}_{2}: \mathrm{HfO}_{2}$, with two bilayers of $\mathrm{SiO}_{2}$ and $\mathrm{Ta}_{2} \mathrm{O}_{5}$ on top, has been demonstrated to fully meet the requirements of ET-LF on $\mathrm{CTN}_{\mathrm{D}}$ [55] and on optical absorption for the first time.

There are many other challenges to be overcome to realize the cryogenic Einstein Telescope, but this coating design is an important step towards the detector being able to meet its goal of a factor of 100 improvement in sensitivity over aLIGO at frequencies around $10 \mathrm{~Hz}$.

We are grateful for the financial support provided by STFC under grants ST/L000946/1 and ST/L000938/1, by the Royal Society (RG110331) and the University of Glasgow. IWM is supported by a Royal Society Research Fellowship. We are grateful to the International Max Planck Partnership for Measurement and Observation at the Quantum Limit for support, and we thank our colleagues in the LSC and Virgo collaborations and within SUPA for their interest in this work. We thank M Hart for helpful comments. We would like to thank M. Pitkin for help with low frequency GW sources. This paper has LIGO Document number LIGO-P1800241.
* iain.martin@glasgow.ac.uk 
[1] B. P. Abbott, R. Abbott, T. D. Abbott, M. R. Aber-360 nathy, F. Acernese, K. Ackley, C. Adams, T. Adams,361 P. Addesso, R. X. Adhikari, et al. (LIGO Scientific Col-362 laboration and Virgo Collaboration), Phys. Rev. Lett.363 116, 061102 (2016)

[2] B. P. Abbott, R. Abbott, T. D. Abbott, M. R. Aber-365 nathy, F. Acernese, K. Ackley, C. Adams, T. Adams, 366 P. Addesso, R. X. Adhikari, et al. (LIGO Scientific Col-367 laboration and Virgo Collaboration), Phys. Rev. Lett. 368 116, 241103 (2016)

[3] B. P. Abbott, R. Abbott, T. D. Abbott, F. Acernese, ,370 K. Ackley, C. Adams, T. Adams, P. Addesso, R. X. Ad-371 hikari, and V. B. Adya (LIGO Scientific and Virgo Col-372 laboration), Phys. Rev. Lett. 118, 221101 (2017).

[4] B. P. Abbott, R. Abbott, T. D. Abbott, F. Acernese,374 K. Ackley, C. Adams, T. Adams, P. Addesso, R. X. Ad- 375 hikari, and V. B. Adya (LIGO Scientific Collaboration 376 and Virgo Collaboration), Phys. Rev. Lett. 119, $1_{14101}$ (2017)

[5] B. P. Abbott, R. Abbott, T. D. Abbott, F. Acernese,379 K. Ackley, C. Adams, T. Adams, P. Addesso, R. X. Ad-380 hikari, V. B. Adya, et al. (LIGO Scientific Collaboration 381 and Virgo Collaboration), Phys. Rev. Lett. 119, 161101 382 (2017)

[6] B. P. Abbott, R. Abbott, T. D. Abbott, M. R. Aber-384 nathy, F. Acernese, K. Ackley, C. Adams, T. Adams, 385 P. Addesso, R. X. Adhikari, et al. (LIGO Scientific Col-386 laboration and Virgo Collaboration), arXiv:1811.12907 387 (2018)

[7] B. P. Abbott, R. Abbott, T. D. Abbott, M. R. Aber- 389 nathy, F. Acernese, K. Ackley, C. Adams, T. Adams, 390 P. Addesso, R. X. Adhikari, et al. (LIGO Scientific Col-391 laboration and Virgo Collaboration), Phys. Rev. Lett. 392 116, 131103 (2016)

[8] B. P. Abbott, R. Abbott, T. D. Abbott, M. R. Aber-39 nathy, F. Acernese, K. Ackley, C. Adams, T. Adams, 395 P. Addesso, R. X. Adhikari, et al. (LIGO Scientific Col-396 laboration and Virgo Collaboration), Classical and Quan-397 tum Gravity 32, 074001 (2015)

[9] T. Accadia et al. (VIRGO), JINST 7, P03012 (2012) $\quad 399$

[10] G. M. Harry, A. M. Gretarsson, P. R. Saulson, S. E. Kit-400 telberger, S. D. Penn, W. J. Startin, S. Rowan, M. M. Fe-401 jer, D. R. M. Crooks, G. Cagnoli, J. Hough, and N. Nak-402 agawa, Classical and Quantum Gravity 19, 897 (2002), 403

[11] K. Somiya, Classical and Quantum Gravity 29, 124007404 (2012).

[12] Y. Aso, Y. Michimura, K. Somiya, M. Ando,406 O. Miyakawa, T. Sekiguchi, D. Tatsumi, and H. Ya-407 mamoto (The KAGRA Collaboration), Phys. Rev. D 88, 108 043007 (2013)

[13] M. Abernathy, F. Acernese, P. Ajith, B. Allen, P. Amaro-410 Seoane, N. Andersson, S. Aoudia, P. Astone, B. Krish-411 nan, L. Barack, et al., "Einstein gravitational wave tele- 12 scope (et) conceptual design study," (2011).

14] M. Pitkin, Monthly Notices of the Royal Astronomical ${ }_{114}$ Society 415, 1849 (2011)

15] D. Falta, R. Fisher, and G. Khanna, Phys. Rev. Lett.t16 106, 201103 (2011)

[16] G. M. Harry, M. R. Abernathy, A. E. Becerra-Toledo,418 H. Armandula, E. Black, K. Dooley, M. Eichenfield, 419 C. Nwabugwu, A. Villar, D. R. M. Crooks, G. Cagnoli,420 J. Hough, C. R. How, I. MacLaren, P. Murray, S. Reid,421 S. Rowan, P. H. Sneddon, M. M. Fejer, R. Route, S. D.422 Penn, P. Ganau, J.-M. Mackowski, C. Michel, L. Pinard,423 and A. Remillieux, Classical and Quantum Gravity 24, 405 (2007)

[17] Characterization of Advanced LIGO Core Optics, Vol. 66 (2017).

[18] I. Martin, H. Armandula, C. Comtet, M. M. Fejer, et al., Classical and Quantum Gravity 25, 055005 (2008).

[19] I. W. Martin, R. Bassiri, R. Nawrodt, M. M. Fejer, A. Gretarsson, E. Gustafson, G. Harry, J. Hough, I. MacLaren, S. Penn, S. Reid, R. Route, S. Rowan, C. Schwarz, P. Seidel, J. Scott, and A. L. Woodcraft, Classical and Quantum Gravity 27, 225020 (2010).

[20] I. W. Martin, R. Nawrodt, K. Craig, C. Schwarz, et al., Classical and Quantum Gravity 31, 035019 (2014)

[21] M. Granata, K. Craig, G. Cagnoli, C. Carcy, W. Cunningham, J. Degallaix, R. Flaminio, D. Forest, M. Hart, and J.Hennig, Opt. Lett. 38, 5268 (2013)

[22] E. Hirose, K. Craig, H. Ishitsuka, I. W. Martin, N. Mio, S. Moriwaki, P. G. Murray, M. Ohashi, S. Rowan, Y. Sakakibara, T. Suzuki, K. Waseda, K. Watanabe, and K. Yamamoto, Phys. Rev. D 90, 102004 (2014)

[23] M. E. Fine, H. van Duyne, and N. T. Kenney, Journal of Applied Physics 25, 402 (1954).

24] J. W. Marx and J. M. Sivertsen, Journal of Applied Physics 24, 81 (1952).

[25] A. Schroeter, R. Nawrodt, R. Schnabel, S. Reid, I. Martin, S. Rowan, C. Schwarz, T. Koettig, R. Neubert, M. Thürk, W. Vodel, A. Tünnermann, K. Danzmann, and P. Seidel, arXiv (2007), arXiv:0709.4359 [gr-qc]

[26] D. G. Matei, T. Legero, S. Häfner, C. Grebing, R. Weyrich, W. Zhang, L. Sonderhouse, J. M. Robinson, J. Ye, F. Riehle, and U. Sterr, Phys. Rev. Lett. 118, 263202 (2017)

[27] M. A. Green and M. J. Keevers, Progress in Photovoltaics: Research and Applications 3, 189 (1995).

[28] P. G. Murray, I. W. Martin, K. Craig, J. Hough, R. Robie, S. Rowan, M. R. Abernathy, T. Pershing, and S. Penn, Phys. Rev. D 92, 062001 (2015).

[29] X. Liu, D. R. Queen, T. H. Metcalf, J. E. Karel, and F. Hellman, Phys. Rev. Lett. 113, 025503 (2014).

[30] R. Birney, (2018), article in preparation.

[31] J. Steinlechner, I. W. Martin, R. Bassiri, A. Bell, M. M. Fejer, J. Hough, A. Markosyan, R. K. Route, S. Rowan, and Z. Tornasi, Phys. Rev. D 93, 062005 (2016)

[32] J. Steinlechner, I. W. Martin, A. S. Bell, J. Hough, M. Fletcher, P. G. Murray, R. Robie, S. Rowan, and R. Schnabel, Phys. Rev. Lett. 120, 263602 (2018)

[33] M. R. Abernathy, S. Reid, E. Chalkley, R. Bassiri, et al., Classical and Quantum Gravity 28, 195017 (2011).

[34] S. V. Ushakov, A. Navrotsky, Y. Yang, S. Stemmer, et al., physica status solidi (b) 241, 2268 (2004).

[35] R. Bassiri, The atomic structure and properties of mirror coatings for use in gravitational wave detectors, Ph.D. thesis, University of Glasgow (2012).

[36] "CSIRO,"

[37] D. McGuigan, C. Lam, R. Gram, A. Hoffman, et al., Journal of Low Temperature Physics 30, 621 (1978).

[38] R. Nawrodt, C. Schwarz, S. Kroker, I. W. Martin, et al., Classical and Quantum Gravity 30, 115008 (2013)

[39] R. P. Netterfield, M. Gross, F. N. Baynes, K. L. Green, et al., Proc. SPIE 5870, 58700H (2005).

[40] D. Gopireddy and C. G. Takoudis, Physical Review B 77, 205304 (2008).

[41] R. R. Robie, Characterisation of the mechanical properties of thin-film mirror coating materials for use in fu- 
ture interferometric gravitational wave detectors, Ph.D.449 thesis, University of Glasgow (2018).

[42] Temperature-dependent absolute refractive index measurements of synthetic fused silica, Vol. 6273 (2006).

[43] M. M. Fejer, S. Rowan, G. Cagnoli, D. R. M. Crooks, 453 A. Gretarsson, G. M. Harry, J. Hough, S. D. Penn, P. H.454 Sneddon, and S. P. Vyatchanin, Phys. Rev. D 70, 082003 (2004)

[44] M. Abernathy, Mechanical properties of coating mate-457 rials for use in the mirrors of interferometric gravita-458 tional wave detectors, Ph.D. thesis, University of Glasgow459 (2012).

[45] K. Craig, Studies of the mechanical dissipation of thin 461 films for mirrors in interferometric gravitational wave de-462 tectors, Ph.D. thesis, University of Glasgow (2015).

463

[46] J. Franc, N. Morgado, R. Flaminio, R. Nawrodt, I. Mar-464 tin, L. Cunningham, A. Cumming, S. Rowan, and ${ }_{465}$ J. Hough, arXiv (2009), 0912.0107 [gr-qc].

466

[47] D. T. Pierce and W. E. Spicer, Phys. Rev. B 5, 3017.67 (1972)

48 2 L. Pinard, C. Michel, B. Sassolas, L. Balzarini, J. De-469 gallaix, V. Dolique, R. Flaminio, D. Forest, M. Granata,470 B. Lagrange, N. Straniero, J. Teillon, and G. Cagnoli,471 Appl. Opt. 56, C11 (2017)

[49] B. S. Berry and W. C. Pritchet, IBM J. Res. Dev. 19,
334 (1975).

[50] S. Barta, Journal of Applied Physics 75, 3258 (1994)

[51] A. Alexandrovski, M. Fejer, A. Markosian, and R. Route (2009) pp. 71930D-71930D-13.

[52] B. P. Abbott, R. Abbott, T. D. Abbott, M. R. Abernathy, F. Acernese, K. Ackley, C. Adams, T. Adams, P. Addesso, R. X. Adhikari, V. B. Adya, C. Affeldt, M. Agathos, K. Agatsuma, N. Aggarwal, O. D. Aguiar, L. Aiello, A. Ain, P. Ajith, B. Allen, A. Allocca, P. A. Altin, S. B. Anderson, W. G. Anderson, K. Arai, M. C. Araya, C. C. Arceneaux, J. S. Areeda, N. Arnaud, K. G. Arun, S. Ascenzi, G. Ashton, M. Ast, S. M. Aston, P. Astone, P. Aufmuth, C. Aulbert, S. Babak, P. Bacon, M. K. M. Bader, P. T. Baker, F. Baldaccini, G. Ballardin, et al. (LIGO Scientific Collaboration and Virgo Collaboration), Phys. Rev. Lett. 116, 131103 (2016)

[53] J. Steinlechner, I. W. Martin, J. Hough, C. Krüger, S. Rowan, and R. Schnabel, Phys. Rev. D 91, 042001 (2015)

54] W. Yam, S. Gras, and M. Evans, Phys. Rev. D 91, $042002(2015)$

[55] At a slightly more conservative (and perhaps more likely) operating temperature of $20 \mathrm{~K}, \mathrm{CTN}_{\mathrm{D}}$ would only be a factor of 1.5 above the ET-LF design. 